\title{
Analysis of How to Strengthen Agricultural Supply-side Reform Locally
}

\author{
Yanping Liu \\ Jingchu University of Technology, Jingmen Hubei 448000, China
}

\begin{abstract}
Keywords: Rural Economy; Supply-side structural reform; reform direction.
\end{abstract}
\begin{abstract}
China is a big agricultural country, and agriculture, as the primary industry, plays a very important role in the economic development. With the rapid economic development of our country, there is a big gap between rural areas and urban area's economic development. In order to promote the better development of our country' s agricultural economy, the central government implements the agricultural supply-side structural reform to effectively promote the quality and quantity of agricultural products and the seamless connection between place of origin and consumption area through rural self-adjustment, thus promoting the better development of rural economy.
\end{abstract}

\section{Introduction}

The CPC Central Committee Rural Work Conference was held in Beijing from December 24 to 25, 2015. It is presented at the meeting that agricultural supply-side structural should be strengthened, the quality and quantity of agricultural products should be promoted to satisfy the demand of consumers, agricultural products and consumer goods need to be integrated effectively, rural production structure will be changed, thus promoting the development of rural economy. So how to strengthen the agricultural supply-side reform locally?

\section{In-Depth Discussion and Understanding of Agricultural Supply-Side Structural Reform}

After putting forward the concept of strengthening the agricultural supply-side reform, many deputies also proposed to enlarge the reform of agricultural structure, effectively, effectively increase the quantity and quality of agricultural products, reduce the supply of poor quality agricultural products, and truly improve the quality of agricultural products, thus effectively improving the development of rural economy. Among these, it is necessary to increase investment in agricultural production, innovate cultivation techniques, and change the rural economy structure so as to increase the output and quality of agricultural products and ensure safe supply. In addition, the proportion of agricultural resources in the market should be increased, so that it truly reaches the supply-demand balance and promote the healthy development of our society.

When carrying forward the agricultural supply-side structural reform, the major work is solving the problems of destocking, cost reduction and addressing weak links, which also means dealing with the relationship between addition and subtraction. Therefore, we must adjust the structure of agricultural products, increase the supply of safe, green, and organic agricultural products, raise efficiency, and increase the production of high benefit products. In addition, unsalable agricultural products should be made effective adjustment to reduce inventory levels and the supply of low-quality or ineffective agricultural products should be reduced.

Specifically speaking, first of all, it is necessary to accelerate the sale of agricultural products stocks, because the longer it socks, the harder it becomes to sell, which will eventually be putrid, causing a waste of agricultural products. Second, the processing and transformation of agricultural products should be accelerated and the structure of agricultural production should be adjusted. The largest amount of Chinese agricultural products are corns, so the target is to destock corn. At the same time, production structure will be adjusted to reduce corn planting and production and increase the acquisition of corn in downstream industry. In addition, we must also complete policies of agricultural subsidies and grain collection and storage to ensure providing farmers with better quality and convenient services, promote the development of agricultural product processing industry, and 
truly achieve the production, processing and sales of industrialized processes. For example, in actual agricultural development, it is necessary to increase the scale of planting, control planting costs, reduce the use of pesticides and fertilizers, use some natural organic fertilizers as much as possible, strengthen various infrastructures in the agricultural production process, and complete the entire industrial chain, which will increase the competitiveness of agricultural products in the market and promote better development of agriculture.

Always making agriculture the first position is the foundation of comforting people. Therefore, in the new era of socialism, in order to promote better development of agriculture, we must find the balance in development, adjust the structure of agricultural production, effectively reform agriculture, promote a healthier development of rural economy, and thus build a well-off society in an all-round way.

\section{Strengthen Agricultural Supply-Side Structural Reform Locally}

According to the agricultural supply-side structural reform proposed by the central government, in order to be able to effectively implement this work, a certain local government put forward assured agriculture. Why we have to develop assured agriculture? In fact, it is an in-depth understanding and refinement of the central government's agricultural structural reforms. In the agricultural reform, the ultimate goal is the agricultural products. The security problem is the focus of agricultural products, because in the process of Chinese economic development in recent years, there have been too many food safety issues, which has taken an enormous psychological toll on people. For example, the melamine incident of Sanlu milk power, the waste oil incident, the red duck egg incident, and the emergence of a large number of genetically modified foods, which are still shocking people. Therefore, when reforming agriculture, the issue of food safety must be put on the first stage, and the goal of related reform policies is to make sure people can buy the assured food. How to truly achieve assured agriculture? Locally, starting with its origin and the production of agricultural products, it is necessary to control its quality, and regulate the production, processing, and sales of agricultural products from the rules, strengthen the brand building of foods, increases brand effect, and improve people's confidence in the purchase of foods. What's more, local governments can also start with the operation of capital to adjust the agricultural structure so as to truly promote the healthy and rapid development of agriculture.

After proposing such an agricultural reform strategy, what actions should local governments take? First of all, the government should increase the investment of funds, open up the communication channels between market and agriculture by government capital, and effectively combine the needs of agricultural production and market supply. For example, applying advanced Internet equipment to current agricultural production allows farmers to make effective adjustments of market information and change their own planting methods in time. In addition, various hi-tech technologies should be fully utilized in planting and production so as to develop ecological and circulatory agriculture. Agriculture is divided into three major sections, one is the traditional agricultural upgrading section, which is mainly to promote the circulation development of agricultural. One is the modern agricultural production sector, mainly the development of ecological agriculture, and the other is the comprehensive reform of experimental agricultural sector, mainly the development of smart agriculture. Through such a meticulous and effective division, the agricultural supply-side structural reform can be well implemented.

At the seminar on how to implement the agricultural supply-side structural reform, the local government first highly evaluated it and at the same time, carried out in-depth discussions and analysis which grasped the pulse of the rural agricultural supply-side reform.

In the specific discussion, experts believe that the main problems in current agricultural development are contradictions in production structure and supply-side conflicts. To effectively solve these problems, the first thing to do is to improve product quality and food safety, which requires constant innovation in the concept of agricultural development and promote the development of ecological and circular agriculture in China. In addition, while ensuring the quality of agricultural 
production, it is also necessary to continuously increase the output of agricultural products and the acquisition value of agricultural products so as to truly encourage farmers to obtain higher incomes. In fact, in the process of socialist economic development, farmers were the most suffering people because the government had to supported the industry through agriculture in the early stage. The government purchased food through low prices to ensure the development of the industry and the rapid construction of the city. In terms of the system, rural villagers were limited from influxing into the cities, resulting in uncultivated land and social instability. However, in the development of modern society, the gap between the rich and the poor is getting bigger and bigger. If the relevant policies are not reformed in time, it will inevitably cause social unrest.

When solving the problems of agricultural product quality and food safety, as well as improving its competitiveness in the market, it is necessary for the government, enterprises, and social organizations to integrate themselves together so as to promote the effective reform of agriculture. In the years of reforms in agricultural production, it has been found that one of the most important issues that needs to be resolved is to increase the enthusiasm for production of farmers. Because in the modern society, there has been a large number of peasant loss, and many children in rural areas have gone to school in cities and eventually settled in there, which has drastically reduced the number of people engaged in agricultural production. Nowadays, if we do not strengthen agricultural reform and increase relevant treatment and economic level, it will eventually lead to the emergence of a large number of wasteland and uncultivated crops. Therefore, when implementing specific agricultural supply-side structural reform, it is necessary to mobilize the enthusiasm for production of farmers and improve their sense of responsibility. The so-called "assured agriculture" is not only the production of assured products, but also the assurance that farmers can produce safely. If peasants engage in agricultural production, but finally can't earn as much as in the cities and cannot solve their problems of food and clothing, how can they be willing and able to work on agricultural production?

When developing "assured agriculture", the local government needs to have an in-depth understanding of its connotation. Assured agriculture contains a lot, and the food safety issue is only from the consumer's point of view. If assured agriculture can't not be developed better, it may also cause damage to our country's economy. Therefore, in the development of assured agriculture, it is necessary to not only ensure consumers' confidence, but also to effectively protect the entire ecological environment.

The key word of "assured agriculture" is "assured." The analysis of "assured" can be divided into three main parts. The first is to ensure the quantity in the agricultural production process, which refers to increase the quantity of agricultural products to effectively solve the problem of food and clothing. The second part is to control the quality of agricultural products and make it reassuring. That is to say, the food that people buy should be non-toxic and harmless, green and healthy, and it should not endanger people's life and health. The third is to ensure the sustainable development of agricultural production, which means to ensure the long-term development of agriculture, rather than suddenly stop. The agricultural supply-side structural reform proposed by China now is to find a balance point from these three aspects, so as to promote better development of rural economy. When reforming agricultural production, first it is necessary to allow agriculture to enter the market, increase agricultural production capacity and control ability to the entire market through modern science and technology, so as to continuously promote the transformation of agricultural production methods. And in the adjustment of market mechanism, farmers will continue to improve the quality of their own agricultural products in order to open up their market, and to build a relevant integrity system to ensure a more complete industry chain.

Regarding as development of assured enterprises, all parties in the society should give full play to their role and thus promote the further development of our agriculture. The first is the government. When carrying out agricultural supply-side structural reform, the government must clarify its own responsibilities and orientation, give full play to its main role, and do a good job in related guidance. For example, destocking, cost reduction, and short-cutting are the most important work. The government needs to strengthen comprehensive training for rural farmers and increase the support for agriculture so as to promote better development of agriculture. Second, the main task of social 
organization is to do a good job in the evaluation of agricultural products. They should be fair and just during this process and establish an excellent brand. Third, the main role of enterprises in agricultural production reform is to develop relevant e-commerce and fully utilize the current situation of market economy development to improve the economic benefits of agricultural production. Fourth, as for farmers, it is necessary to fully mobilize their enthusiasm to participate in the agricultural production process, so as to truly promote agricultural reform and rural economic development.

\section{Conclusion}

In conclusion, agriculture has always played an important basic role in in the process of the rapid development of Chinese modern economy. With the improvement of people's living standards, they have also put forward higher requirements for agricultural products. Therefore, in the process of modern agricultural development in China, it is necessary to strengthen agricultural supply-side structural reform, change the structure of agricultural industry, control the cost of agricultural products, increase their output and quality, meet people's quality demand for agricultural products, and increase their competition in the market, thus promoting better development of Chinese rural economy.

\section{Acknowledgements}

This paper is a research result of the 2017 research project Exploration on Promoting the Agricultural Supply-Side Reform (Project No.: 2017zgng08) supported by ZHONG GUO NONG GU Research Center of Jingchu University of Technology.

\section{References}

[1]. Jia Shiwei, Li Wanying, Li Kai. Analysis of Cultural Targeted Poverty Alleviation under the background of Agricultural Supply-side Reform. [J]. Research of Capital, 2017,13(00):119-124.

[2]. Jia Shiwei, Li Wanying, Li Kai. Analysis of Cultural Targeted Poverty Alleviation under the background of Agricultural Supply-side Reform. [J]. Research of Capital, 2017,13(00):119-124.

[3]. Chen Xiwen. Promote Agricultural Supply-side Reform and Breakthrough Reform Deep-water Zone----Speech at the Hunan Precision Agriculture Base Forum [J]. Chinese Village Discovery, 2017(02):1-10.

[4]. Deng Xiuying, Zhu Jinxun, Helin, Zhang Qingyong, Fan Rongrong, Li Rui. Analysis and Discussion on "Internet Plus" Agriculture Supply-side Reform----Taking an example of Wande Town, Jinan City and Shouguang City, Weifang City [J]. China Collective Economy, 2017(08):48-49.

[5]. Chen Wensheng. Problems to be Solved when Promoting Agricultural Supply-side Reform [J]. Chinese Country Discovery, 2016(02):41-47. 